\section{¿PARA QUÉ ME SIRVE MI CUERPO?}

\section{WHAT IS MY BODY FOR?}

ESMERALDA ESPINOSA LÓPEZ1

Si nos basamos en la idea del capítulo 10 de Testo Yonqui: Pornopoder (Preciado, 2008) y la idea de que la pornografía es un dispositivo virtual masturbatorio, podemos comprender que ésta también pertenece al progreso de la Cultura visual (en adelante CV). Tanto la pornografía como la CV han hecho que los cuerpos sean un producto de la cultura de masas, buscando la modificación del mismo para llegar a la perfección vendida por los productos, los lugares y la idealización

' Universidad Autónoma de Querétaro, México. Correo electrónico: esmeralda84_el@outlook.com REVISTA ESTUDIOS DE GÉNERO, LA VENTANA, NÚM. 53, ENERO-JUNIO DE 202I PP. 485-490, ISSN I405-9436 E-ISSN: 2448-7724 de los cuerpos bellos, logrando el progreso de la industria y el consumismo, sin llegar a una satisfacción completa, únicamente desarrollando una necesidad de consumismo que se controla con la adquisición, queriendo perfeccionar todo aquello que se posee; generando en la CV la misma estimulación para la producción de placer.

La imagen es ahora lo que rige al mundo, aunque cambia constantemente y su visualidad dura únicamente segundos, los espectadoresgeneradores de las mismas, necesitan ser vistos para poder satisfacer su necesidad de formar parte de la nueva sociedad. Todo lo perteneciente a la pornografía y a la industria cultural tiene la posibilidad (convertida ya en una necesidad) de tener una reproducción técnica como la transformación digital (toda imagen creada y capturada puede ser encontrada en la red), difusión audiovisual (las redes sociales permiten este intercambio de imágenes, momentos e información) y la 
$486 \longrightarrow$ La Ventana, Núm. 53/2021

teatralización (mostrando lo que se quiere que sea la vida y no lo que en realidad es) logrando así el efecto mariposa que Preciado menciona en Testo Yonqui.

La exclusión de la pornografía del mundo público ha hecho que todo aquello que muestre un cuerpo recibiendo/dando placer sea relegado a algo tabú, prohibido para cualquier persona y de reproducción ilegal en cualquier medio digital y para cualquier persona, comparándose con los freak shows $\mathrm{o}$, donde las personas que la ven son considerados enfermos mentales y aquellos que la realizan son vistos como criminales; su aceptación ha progresado así como la mentalidad de la sociedad, pero continúa sin ser vista como arte, sino como un promocional de la venta de cuerpos perfectos.

Si vemos la realidad de la nueva sociedad y su desarrollo tecnológico, la industria pornográfica, la farmacología y la propaganda han progresado de manera colosal, pues todas dependen una de otra para su progreso, si les damos un lugar a cada una para lograrlo en el campo económico de la industria: la pornografía es la generadora del placer, del querer conseguir aquello idealizado; la farmacología (incluyendo fármacos y operaciones) como medio para conseguir esa idealización y cumplir con los estándares de belleza impuestos por la sociedad, y a la propaganda y la reproducción de lo porno como uno de los mayores propulsores para lograr que el comercio fluya y se obtengan ganancias miIlonarias. Al cuerpo se le ve como un producto o una mercancía rentable, el cual busca estándares de belleza anormales que sólo se logran por medio del consumismo.

Otra relación importante (aunque no exclusiva, ya que el performance no se basa únicamente en la desnudez del cuerpo y la introducción de cosas en el mismo) es la del performance con la pornografía, la cual hace que algunos actores de la industria presenten tra- 


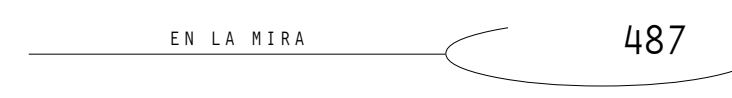

bajos donde muestren su cuerpo como algo más allá de sólo un receptáculo de placer -Annie Sprinkle- o como el sonado caso del acontecimiento en la UBA en Buenos Aires con su "miércoles de placer" donde la explicación fue que "el posporno llega a las Sociales, se pasea por los pasillos de la facultad y va sexualizando todo a su alrededor. Una propuesta para ampliar el imaginario pornográfico y experimentar otras formas sexualizadas de habitar el espacio universitario". La forma de ver lo pornográfico se transforma, ya no sólo muestra fantasías y ficciones, sino que ahora busca "profundizar" el tema de la sexualidad con una perspectiva artística — no se puede decir que todos los trabajos performáticos que implican desnudos y penetraciones refieran esta idea, pero sí están basados en diálogos teóricos - haciendo que el espectador ya no sólo sea un receptor involuntario, si no que se transforma en un espectador de arte. Esta nueva representación cambia la forma en la que se ven los artistas, dejan su papel de actor, de puta, de cosa, para convertirse en críticos de su actividad. Reflexionando y transgrediendo acerca de sus vivencias y de lo teórico se puede obtener de su experiencia, recuperando ahora su identidad y participando de manera activa como sujetos dentro de la virtualidad.

Si se hace un estudio acerca de la evolución de la industria farmacopornográfica, la hotelería es una de las que ha tenido mayor progreso, siendo los moteles los más ventajosos éste argumento se obtiene a través de la visita a aplicaciones de recomendación de lugares o por videos subidos en la plataforma de YouTube donde se investigan este tipo de lugares-, todos han volteado hacia el mundo hipersexualizado, donde todo lo que vende es aquello que muestra algo desnudo, semidesnudo, o que provoca una cierta excitación; ya sea por morbo o por el mero placer de acceder a la información, su uso y demanda ha 
$488 \longrightarrow$ La Ventana, Núm. 53/2021

rebasado aquellos límites que la dejaban en el tabú convirtiéndolo ahora en un mundo completamente nuevo y en el cual puede surgir algún tipo de investigación —claro ejemplo es el que nos brinda la pospornografía-

Como algunos investigadores proponen sobre el concepto de la mirada y la visualidad (Debray, 1994; Guasch, 2003; Jay, 1993), el mundo ha sido tan atacado por el progreso de la industria, la propaganda y la tecnología, que ahora el texto pasa a segundo término y las personas sólo son atraídas por medio de la imagen, la atracción hacia sus formas, sus colores y no su contenido - porque sólo atrae su apariencia, la cuestión de su por qué no es relevante para una sociedad líquida e inmersa en la fugacidad de los momentos - puede decirse que por ello la industria farmacopornográfica ha tenido mayor auge, si una imagen es atractiva, entonces el receptor se excita y surge la necesidad de cumplir con esa obtención de placer para ser un medio participativo; regresamos a la idea de que todo es DAR y RECIBIR. Igual que cualquier otra industria que contiene imagen, la pornografía ha pasado por tres etapas de evolución: la que fue puesta en papel, para pasar hacia los medios digitales como la televisión y evolucionar hasta el medio virtual como lo son los canales en diversas plataformas o transmisiones en vivo; se necesita del progreso en esta industria porque es donde las fantasías y los placeres se ven cumplidos y generan la necesidad de no hacerlo momentáneo, sino desearlo constantemente para volverlo permanente; consumismo y pornografía van de la mano.

El criterio de perfección mostrada en los cuerpos pornográficos es el que rige los estándares de belleza y perfección en la sociedad general, lo que se menciona como "verdad corporal" y en las mujeres se agrega a la belleza como "norma". Como nos menciona Elsa Muñiz (2015) en su texto "Un juego de ficciones: salud, belleza y perfec- 


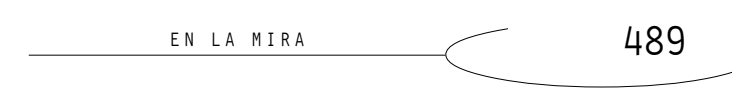

ción" la belleza por las normas sociales ha alcanzado esa demanda que va más allá de ser algo que agrade a la vista, sea generador de placer y aqueIlo con equilibrio, se dirige ahora hacia la obtención del éxito social, de la mejora en las condiciones de vida, ya no es un adjetivo sino una función primordial social; la belleza se mide por los defectos que hay que transformar.

En conclusión, podemos observar que el cuerpo es necesario para realizar la industrialización, ya que él mismo genera y recibe todo aquello que implique un intercambio económico e industrializado. Se requiere de la ayuda de todos los medios publicitarios para que se genere esa excitación y deseo para generar ingresos económicos que ayuden al progreso industrial. La sociedad como tal ya no progresa en cuanto a historicidad y cultura, su cultura ahora es generadora de momentos en el espacio virtual, la observación rápida y vacía de lo logrado por sus miembros activos en la sociedad líquida, todo es un medio de compraventa, nada contiene un sentido o significado, se busca mantener la vida de "ensueño" de cada sujeto, pero nunca se busca satisfacer el espacio real y temporal, únicamente a través de la generación de aceptación por medio del desarrollo de su economía y su "belleza" industrial; todo estándar antiguo para la evaluación de la belleza se ha desvanecido y ha sido sustituido por la medición de la aceptación por sus ingresos económicos y su desarrollo de la perfección corporal y los medios digitales.

Farmacopoder y Pornopoder son las nuevas reglas que rigen la sociedad, nunca será aceptado como tal el término, ni la vista pornográfica de los cuerpos y las comparativas industriales, sociales y económicas con aquello que sucede dentro de la industria pornográfica, pero igual que como sucede con cualquier verdad expresada, nunca es bien aceptada y siempre será negada. 


$490 \quad$ La VENTANA, NúM. 53/2021

\section{Bibliografía}

Debray, R. (1 994). Vida y muerte de la imagen. Historia de la mirada en Occidente. Barcelona: ediciones Paidós.

Guasch, A. (2003). Un estado de la cuestión. Estudios Visuales, I, 816.

JAy, M. (1993). Regímenes escópicos de la modernidad. Madrid: Ediciones Paidós.

MuñIz, E. (2015). Un juego de ficciones: salud, belleza y perfección. En A. Diaz y F. Giménez (Coords.), Ficciones del cuerpo (pp. 3 I -66). México: La cifra, Universidad Autónoma Metropolitana.

Preciado, P. B. (2008). Testo Yonqui. Madrid: Espasa Calpe, S. A. 